\title{
Gene Expression in Adult T Cell Leukemia/Lymphoma : Up-Regulation of Matrix Metalloproteinase 2 in Skin Lesions
}

\author{
Kennosuke Karube ${ }^{1,3)}$, Koichi Ohshima ${ }^{1)}$, Makoto Hamasaki ${ }^{1)}$, \\ Takeshi Tsuchiya ${ }^{1)}$, Takahiro Yamaguchi ${ }^{1)}$, Hiroaki Suefuji ${ }^{1)}$, \\ Junji Suzumiya ${ }^{2)}$, Kazuki Nabeshima ${ }^{1)}$, Atae Utsunomiya ${ }^{4}$, \\ Mine $\mathrm{Harada}^{3)}$ and Masahiro Kikuchi ${ }^{1)}$
}

\begin{abstract}
The neoplastic cells of adult T-cell leukemia/lymphoma (ATLL) invade various body organs, typically the lymph nodes (LN) and skin. The present study was designed to clarify the mechanism of invasion, by using a DNA array that allowed comparison of gene expression among ATLL cells in different sites, namely peripheral blood (PB), LN, and skin. The expression of matrix metalloproteinase 2 (MMP-2) mRNA was significantly up-regulated in skin relative to PB. Immunohistochemistry showed higher MMP-2 expression in ATLL cells found in the skin than in LN. Expression of membrane-type1-MMP (MT1-MMP), an activator of pro-MMP2 , was detected in fibroblasts present in the skin stroma. The proportion of MMP-2-positive cells in PB was not different between patients with or without skin invasion. Our results indicate that MMP-2 does not account for migration of ATLL cells to the skin, but once these cells reach the skin, this molecule seems to play an important role in proliferation of ATLL cells and/or their invasion of skin tissue.
\end{abstract}

Key words Adult $\mathrm{T}$ cell leukemia/lymphoma, matrix metalloproteinase 2, skin, invasion

\section{INTRODUCTION}

Adult T cell leukemia/lymphoma (ATLL) is a lymphoproliferative disorder of helper/inducer $\mathrm{T}$ cell origin, caused by human $\mathrm{T}$ lymphotrophic virus type 1 infection $(\mathrm{HTLV}-1)^{1-3}$. ATLL is prevalent in areas endemic for HTLV-1, including south-western Japan and the Caribbean basin ${ }^{4}$. HTLV-1 infection mainly occurs early in life via the breast milk of carrier mothers ${ }^{5}$, and approximately $4-5 \%$ of HTLV1 carriers are thought to develop ATLL after long latency periods, usually 40 to 50 years ${ }^{6}$.

In ATLL, leukaemic cells frequently infiltrate

Received : Oct 18, 2004

Revised: Nov 1, 2004

Accepted: Nov 4, 2004

1) Departments of Pathology and ${ }^{2)}$ Internal Medicine, School of Medicine, Fukuoka University, Fukuoka; ${ }^{3}$ Medicine and Biosystemic Science, Internal Medicine, Medicine and Surgery, Kyushu University Graduate School of Medical Science, Fukuoka, 4) Department of Hematology, Imamura Bun-in Hospital, Kagoshima, JAPAN Adress correspondence and reprint request to Kennosuke Karube, Department of Pathology, School of Medicine, Fukuoka University, Nanakuma 7-45-1, Jonan-ku, Fukuoka 814-0180, JAPAN. organs such as lymph nodes, spleen, liver, and skin? In particular, skin invasion represents a significant difference from other types of lymphomas or leukemias $^{8}$. However, little is known about the underlying molecular mechanisms of this phenomenon, although there have been many reports on molecules associated with ATLL carcinogenesis such as matrix metalloproteinase-9 (MMP-9) ${ }^{9}$, a T-cell differentiation antigen, $\mathrm{MAL}^{10}, \mathrm{p} 21 / \mathrm{wafl}^{11}$, and chemokine I-309 ${ }^{12}$. In most of the above reports, a cell line or peripheral blood samples were analyzed. There is therefore a need for studying tissue samples to identify molecules that could account for ATLL cell invasion into tissue. We used gene expression profiling as an initial step in an attempt to identify molecules differentially expressed in lesions in skin, lymph nodes (LN), and peripheral blood (PB). Our results showed that matrix-metalloproteinase-2 (MMP-2) was up-regulated in ATLL cells in LN and skin compared with PB. Based on these findings, we also used immunohistochemistry and flow cytometry to characterize the expression of this protein in ATLL skin lesions. 


\section{MATERIALS AND METHODS}

\section{Patient samples}

Studies were conducted in 29 ATLL patients, including 9 skin sections, $5 \mathrm{LN}$ sections, and $15 \mathrm{~PB}$ samples. ATLL was diagnosed according to the following criteria: positivity of serum antibodies against HTLV-1 ; morphologic characteristics showing highly convoluted nuclei; $\mathrm{CD} 3+$ and $\mathrm{CD} 4+$ phenotypes; and monoclonal integration of the HTLV-1 proviral genome ${ }^{13}$.

\section{Tissue processing and cell samples from periph- eral blood}

Diagnostic tissue samples from skin and LN were fixed in buffered formalin, embedded in paraffin, and stained with hematoxylin and eosin for routine histologic examination (Fig. 1(A), (B), (C), (D)). Five skin sections and four $\mathrm{LN}$ sections were used for gene expression profiling analysis. These portions of the specimens were precooled in isopentane and frozen in liquid nitrogen. Peripheral blood mononuclear cells (PBMC) were obtained from 15 patients with ATLL. In PB, over $90 \%$ of the PBMC were atypical ATLL cells. Five samples were used for gene expression analysis, and the others were analyzed with a monoclonal antibody $(\mathrm{mAb})$ for MMP-2 (Daiichi Fine Chemical Co., Takaoka JAPAN), using a FACScan analyzer (BectonDickinson, Franklin Lakes, NJ).

\section{Immunostaining}

In these studies, mAbs for MMP-2 and MT-1 MMP (Daiichi Fine Chemical Co.) were used for paraffin-embedded samples.

\section{Microarray procedures}

Total RNA was prepared from frozen biological samples by the guanidinium thiocyanate-phenolchloroform method using the Total RNA Separator kit (Clontech, Paolo Alto, CA). All cDNA microarray analyses were performed using total RNA (3DNA $^{\mathrm{TM}}$ Submicro Expression Array Detection Kit ; Genisphere Inc. Montvale, NJ ; http://www. arrayit.com/DNA-Microarray-Protocols/). Briefly, total RNA was reverse transcribed using the included deoxynucleotide triphosphate mix and reverse transcriptase (RT) primer oligo. The cDNA was mixed with the fluorescent $3 \mathrm{DNA}^{\mathrm{TM}}$ reagent, which included a capture sequence for the 5' end of the RT primer, and then hybridized to DNA chips. In each experiment, fluorescent cDNA probes were prepared from an experimental total RNA sample (Cy5labelled) and a control total RNA sample (Cy3labelled) mixed from a pool of total RNA from PBMC from 20 healthy volunteers. The use of a common control cDNA probe allowed the relative expression of each gene to be compared across all samples.

The cDNA clones were from Cancer Chip ver. 2.1 (Takara Bio, Otsu, JAPAN) (557 genes). Fluorescent images of hybridized DNA chips were obtained using a Scan Array 4000 scanner (http:// www.gsilumonics.com/, GSI Lumonics, Boston, MA). Images were analyzed with QuantArray (GSI Lumonics), and fluorescence ratios (along with numerous quality control parameters) were stored in a custom database. Single spots or areas of the array with obvious blemishes were flagged and excluded from subsequent analysis. A set of clones that consistently behaved poorly across arrays was identified and excluded from all analyses. Fluorescence ratios were calibrated independently for each array by applying a single scaling factor to all fluorescent ratios from each array. This scaling factor was computed so that the median fluorescence ratio of well-measured spots on each array was 1.0.

\section{Data analysis}

All non-flagged array elements for which the fluorescence intensity in each channel was greater than 1.4 times the local background were considered well measured. The ratio values were stored in a table (rows, individual cDNA clones; columns, single total RNA samples). We calculated the mean value of each cDNA probe in skin lesions, LN lesions, and PB. Hierarchical clustering was applied to both axes using the weighted pair-group method with centroid average as implemented in the $\mathrm{J}$ Express (http://www.molmine.com/index.j.html, http://www.ii.uib.no/bjarted/iexpress/, Dr. MolMine; contact@molmine. com). The distance matrices used were Pearson correlation for clustering the arrays and the inner product of vectors normalized to magnitude 1 for the genes. Results were analyzed with tree view (Dr. MolMine; <http:// www.nature.com/cgi-taf/DynaPage.taf?file $=/$ nature/journal/v403/n6769/full/ $>$. 

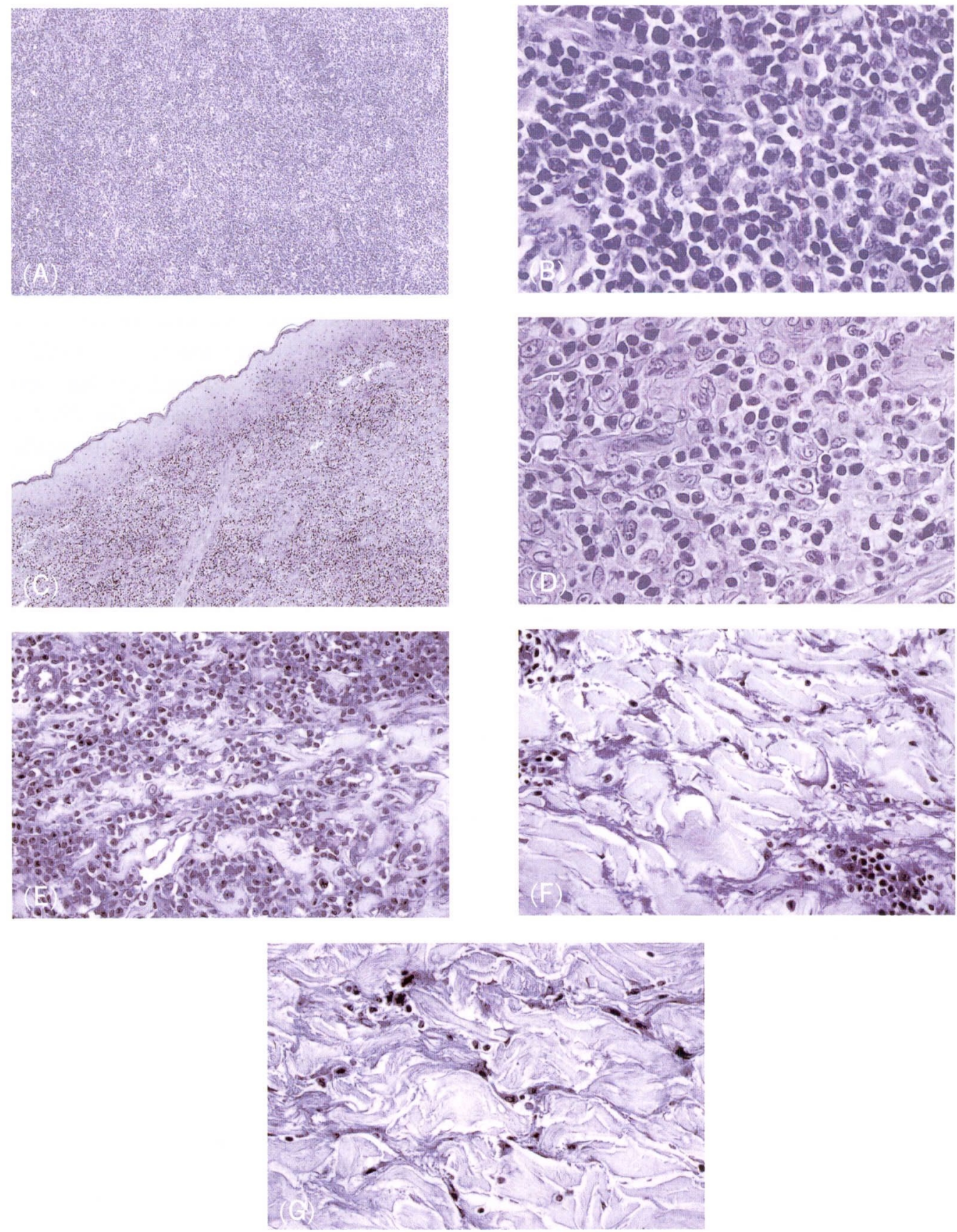

Fig. 1. ATLL morphology and phenotype in each tissue type. (A and B): Lymph node (hematoxylin and eosin), (C and D): Skin, (hematoxylin and eosin), (E and F): Immunostaining with antibodies against MMP-2 in skin lesions. Note the presence of MMP-2-positive lymphoma cells (E) and fibroblasts in the stroma (F). $(\mathrm{G})$ : Immunostaining with antibodies against MT1-MMP in skin lesions. Note the positively-stained fibroblasts in the stroma. All photographs were prepared from paraffin sections. Original magnification: A and C, $\times 20$; B and $\mathrm{D}, \times 200 ; \mathrm{E}, \mathrm{F}$, and $\mathrm{G}, \times 100$. 


\section{RESULTS}

Gene profiling of ATLL cells from lymph nodes, skin, and peripheral blood

LN samples showed diffusely up-regulated gene expression, whereas skin lesions showed a mixed pattern of up- and down-regulated genes. We then compared the profiles of 10 up-regulated and 10 down-regulated genes in skin relative to peripheral blood and LN (Table 1). The expression of MMP-2 was significantly higher in skin than in PB (about 1.8 fold) ( $p$-value $=0.044$, by Student's $t$ test.).

\section{Clustering and classification analysis}

In the tree view of DNA chips from all cases, each site showed a near-perfect segregation. The LN samples exhibited a diffusely up-regulated pattern of gene expression (Fig. 2). Skin samples also showed gene clustering. However, two cases showed diffusely up-regulated gene expression, whereas the other three cases showed a mixed pattern of up- and down-regulated genes. There was no significant difference in the proportion of lymphoma cells between the two groups of skin lesions. The PB samples showed close clustering and a mixed pattern of up- and down-regulated genes (data not shown).

Next, we selected 20 genes that were most different between (1) skin and PB and (2) LN and PB, and performed clustering analysis. In the tree view comparing skin and $\mathrm{PB}$, skin samples exhibited clearly different cluster patterns from PB cases (Fig. $3 a)$. In the tree view comparing $L N$ and $P B, L N$ cases showed close clustering and differed from $\mathrm{PB}$ samples (Fig. 3b). Based on the results of gene profiles, we then focused on the difference between the skin and PB. For the 10 up-regulated genes in the skin, almost all increased molecules were associated with basic skin structure, such as keratin and collagen. However, we also detected MMP-2, an important molecule associated with malignant tumour progression and metastasis ${ }^{14,15}$. Accordingly, we analyzed this molecule in more detail.

Table 1 Comparison of upregulated and downregulated genes in lymph nodes (LN), skin lesions and peripheral blood (PB).

\begin{tabular}{|c|c|c|c|}
\hline \multirow{2}{*}{$\begin{array}{l}\text { LN vs } \mathrm{PB} \\
\text { Up-regulated }\end{array}$} & \multicolumn{2}{|r|}{ Skin vs PB } & \multirow[b]{3}{*}{ Skin/PB } \\
\hline & & & \\
\hline Name & $\mathrm{LN} / \mathrm{PB}$ & Name & \\
\hline EphB2 & 70.13435 & keratin 1 & 10.8898 \\
\hline monokine induced by gamma interferon & 13.23423 & keratin 5 & 5.31798 \\
\hline topoisomerase (DNA) II alpha (170kD) & 7.083324 & keratin 14 & 4.51169 \\
\hline cyclin E1 & 6.976491 & keratin 10 & 4.090596 \\
\hline collagen, type I, alpha 2 & 6.353322 & collagen, type III, alpha 1 & 3.926118 \\
\hline catenin (cadherin-associated protein), alpha 2 & 6.349954 & collagen, type I, alpha 2 & 2.280633 \\
\hline formyl peptide receptor 1 & 6.242536 & $\begin{array}{l}\text { small inducible cytokine subfamily B (Cys-X-Cys), } \\
\text { member } 10\end{array}$ & 1.932534 \\
\hline keratin 14 & 6.203431 & monokine induced by gamma interferon & 1.848092 \\
\hline lumican & 6.056085 & matrix metalloproteinase 2 & 1.795205 \\
\hline thrombopoietin & 6.0262 & collagen, type VI, alpha 3 & 1.729905 \\
\hline \multicolumn{4}{|l|}{ Down-regulated } \\
\hline interleukin 8 & 0.286374 & jun B proto-oncogene & 0.211428 \\
\hline general transcription factor IIH, polypeptide 2 & 0.405093 & interleukin 1 , beta & 0.251978 \\
\hline BCL2-related protein A1 & 0.417415 & $\begin{array}{l}\text { FBJ murine osteosarcoma viral oncogene homolog } \\
\text { B }\end{array}$ & 0.352478 \\
\hline jun B protooncogene & 0.446486 & pro-platelet basic protein & 0.366725 \\
\hline interleukin 1 , alpha & 0.483079 & Rho guanine nucleotide exchange factor (GEF) 1 & 0.376712 \\
\hline fragile histidine triad gene & 0.529086 & plasminogen activator, urokinase receptor & 0.401713 \\
\hline aldolase $\mathrm{A}$, fructose-bisphosphate & 0.553062 & selectin L (lymphocyte adhesion molecule 1) & 0.426048 \\
\hline paxillin & 0.558565 & ras homolog gene family, member G (rho G) & 0.441275 \\
\hline ankyrin 1 , erythrocytic & 0.58108 & interleukin 8 & 0.452102 \\
\hline pro-platelet basic protein & 0.585744 & BCL2-related protein A1 & 0.455703 \\
\hline
\end{tabular}




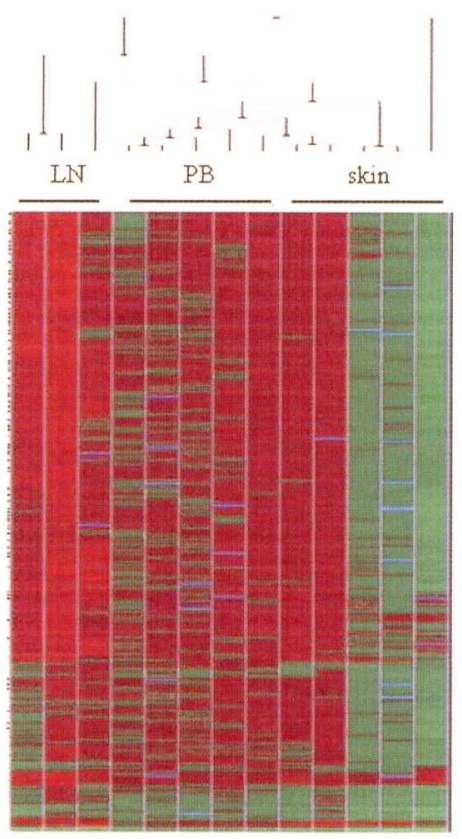

Fig. 2. Gene expression profiles of the three ATLL lesions using 557 genes (Full genes on the Cancer chip 2.1). Dendrogram showing hierarchical clustering of gene expression data (see Methods for algorithm) from three lymph nodes (LN), five skin lesions, and five peripheral blood (PB) samples obtained from patients with ATLL.

\section{Immunohistochemistry}

Immunohistochemistry revealed strong staining for MMP-2 in the skin (Fig. 1E and F) compared with LN (Table 2). MT1-MMP was expressed in fibroblasts but not in lymphoma cells in the skin (Fig. 1G, Table 2). No MT1-MMP expression was noted in LN. Both lymphoma cells and stroma cells were negative for MT1-MMP (Table 2).

\section{Flow cytometric analysis}

Flow cytometric analysis revealed MMP-2 expression in PBMC of ATL. The average proportion of MMP-2-positive cells in PBMC from patients with skin lesions $(24.2 \%$, range, 9.1 to $54.8 \%$ ) was not significantly different from that of cases without skin lesions $(25.6 \%, 14.5$ to $45.0 \%)$.
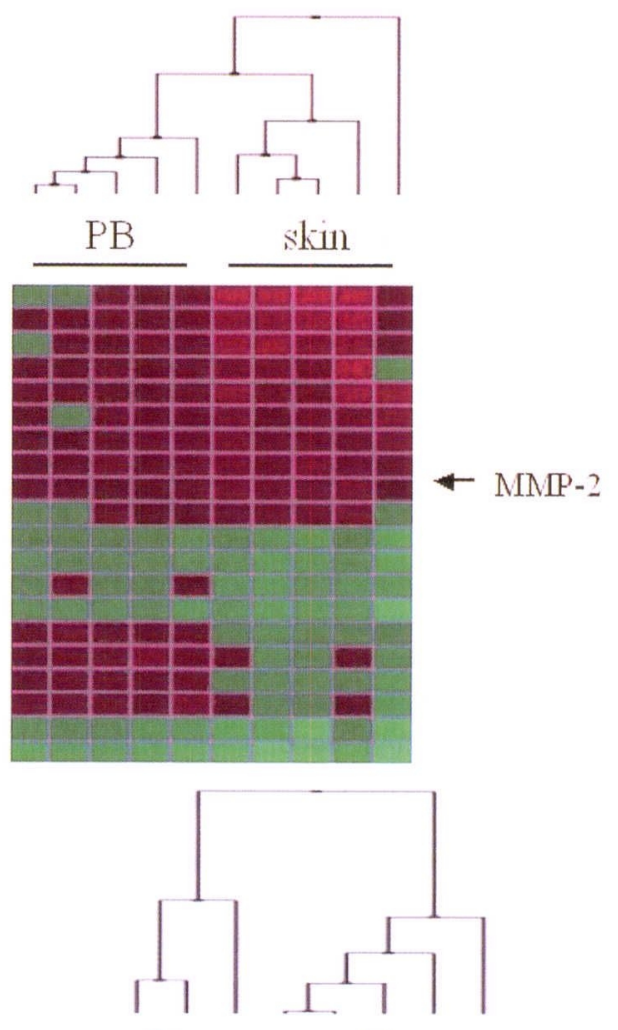

LN

$\mathrm{PB}$

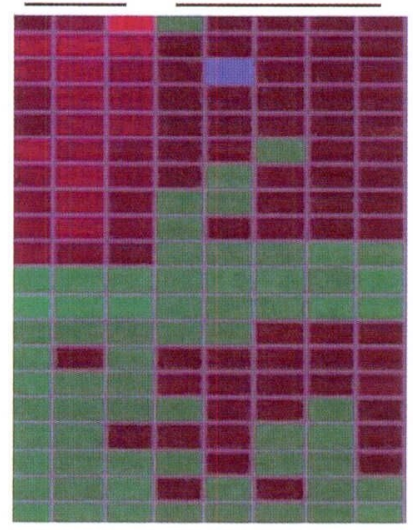

Fig. 3. Comparisons of gene expression profiles from the skin and peripheral blood (PB) (a) and lymph node (LN) and PB (b) of ATLL using the most up- and down-regulated 10 genes. Note that the clarity of each cluster is better than in Fig. 1.

\section{DISCUSSION}

There is little or no information on the mechanisms responsible for ATLL cell invasion into various organs. Recent studies have identified some molecules, mainly adhesion molecules and chemokines, as candidates for ATL cell migration. These include integrin leukocyte function-associated 
Table 2 Comparison of MMP-2 and Ml-MMP expression between skin lesions and lymph nodes in patients with ATLL.

\begin{tabular}{|c|c|c|c|c|}
\hline Case no. & Site of involvement & MMP-2(ATL cells) & MT1-MMP(ATL cells) & MT1-MMP(fibroblasts) \\
\hline 1 & Skin & $2+$ & - & + \\
\hline 2 & Skin & $3+$ & - & + \\
\hline 3 & Skin & $2+$ & - & + \\
\hline 4 & Skin & $2+$ & - & + \\
\hline 5 & Skin & $3+$ & + & + \\
\hline 6 & Skin & $2+$ & - & + \\
\hline 7 & Skin & $2+$ & - & + \\
\hline 8 & Skin & $3+$ & - & + \\
\hline 9 & Skin & $3+$ & \pm & + \\
\hline 10 & Lymph node & - & - & - \\
\hline 11 & Lymph node & + & - & - \\
\hline 12 & Lymph node & + & - & - \\
\hline 13 & Lymph node & \pm & - & - \\
\hline 14 & Lymph node & - & - & - \\
\hline
\end{tabular}

Nine skin lesions and five LN lesions were embedded and labelled as indicated in Materials and Methods and then immunostained for MMP-2 and MT1-MMP.

,$-<5 \%$ of neoplastic cells or fibroblasts stained,,$+>5 \%$ to $<20 \%$ stained, $2+>20 \%$ to $<50 \%$ stained, $3+,>50 \%$ stained.

antigen-1 (LFA-1) ${ }^{13,16,17}$, MMP-99 ${ }^{9}$, vascular endothelial growth factor $(\mathrm{VEGF})^{18}, \mathrm{CCR} 7 / \mathrm{EBI}^{19}$, $\mathrm{CCR} 4^{20}$, MIP1- $\alpha$ and MIP-1 $\beta^{21}$. However, almost all the above previous studies were conducted using cell lines and/or PBMC. In the present study, we used frozen sections of LN, skin, and PB. As a first step, we used cDNA microarrays to compare each lesion to identify novel genetic alterations. In each sample, hierarchical clustering was nearly perfectly segregated according to the tissue. Comparison between skin and PB, and between $\mathrm{LN}$ and PB, showed definite clustering of each lesion. From the genes that showed higher expression levels in the skin relative to $\mathrm{PB}$, we selected MMP-2. MMP-2 was not among the 10 most highly expressed genes in the LN compared with PB.

Matrix metalloproteinases (MMPs) are a family of enzymes that degrade various components of the extracellular matrix $(\mathrm{ECM})^{22,23}$. The $72-\mathrm{kDa}$ gelatinase A (MMP-2) is the most widely distributed of all the MMPs ${ }^{24}$ and is expressed constitutively on a number of cells, including endothelial and epithelial cells. MMPs play an important role in pericellular basement membrane turnover by degrading the main components of the basement membrane (Stetler-Stevenson et al., 1996). They are also important in tumor invasion and metastasis and in the dissemination of hematological malignancies, such as non-Hodgkin lymphoma and acute myelogenous leukaemia $(\mathrm{AML})^{14,15}$. With regard to skin lesions, MMP-2 is reported to be involved in tumor invasion in melanoma ${ }^{25,26}$, Bowen disease, invasive cutaneous carcinoma $^{27}$, basal cell carcinoma ${ }^{28}$ and Mycosis fungoides ${ }^{29}$.

The results of the present study indicate that MMP-2 is also important in the skin invasion of ATLL cells. Immunohistochemical analysis of MMP-2 revealed a stronger immunostaining in ATLL cells in skin lesions than in LN. Based on these findings, two possible scenarios deserve particular attention. The first possibility is that expression of MMP-2 is directly responsible for ATLL cell migration to the skin. Previous studies suggested that HTLV-1-infected $\mathrm{T}$ cells undergo multi-step changes during carcinogenesis to form aggressive leukemic cells ${ }^{30}$. Furthermore, the HTLV-I Tax protein, a $40-\mathrm{kDa}$ transcriptional transactivator of the HTLV-I gene that plays a critical role in cellular transformation in various in vitro models, including $\mathrm{T}$ cells, is reported to transactivate MMP- $9^{9}$. Based on our results, we suggest that migration of leukemic cells to the skin could occur upon induction of MMP-2 expression in such cells. The representative molecule, reported until now, for this scenario is cutaneous lympho-associated Ag (CLA), which has been found to be highly expressed in ATLL cells from $\mathrm{PB}$ of patients with skin lesions ${ }^{13}$. This molecule is a ligand for E-selectin and considered to account for adherence of ATLL cells to the endothelium in the skin.

An alternative explanation for the difference in immunostaining pattern between skin lesions and 
$\mathrm{LN}$ is that the strong expression of MMP-2 in ATLL cells is induced after ATLL cell homing to the skin. To examine this possibility, we analyzed PBMC of ATLL patients with or without skin involvement by flow cytometry. Our results showed that ATLL cells highly expressed MMP-2, but there was no significant difference in the proportion of MMP-2-positive cells between the two groups. These results indicate that the second scenario is more likely. We also examined the expression of MT1-MMP, an activator of pro-MMP- $2^{31}$. MT1-MMP was expressed in fibroblasts in the skin stroma, in contrast to the LN where fibroblasts, including those positive for MT1MMP, were rarely observed. These findings suggest possible activation of MMP on fibroblasts in the skin lesion, which is in agreement with the results of a previous study ${ }^{32}$. In this regard, other reports suggested that MMP-2 and MT1-MMP alter, in an autocrine manner, the proliferation of normal somatic and cancer cells, such as hepatic stellate cells $^{33}$ and breast carcinoma ${ }^{34}$. In our study, the positive staining for MT1-MMP in lymphoma cells, even though such staining was noted in only some cases, may reflect such a mechanism.

In conclusion, the results of the present study indicated that MMP-2 does not account for migration of ATLL cells to the skin, but once these cells migrate to the skin, this molecule seems to play an important role in proliferation of ATLL cells and/ or their invasion of the skin tissue.

\section{REFERENCES}

1 Uchiyama, T., J. Yodoi, K. Sagawa, K. Takatsuki and H. Uchino, Adult T-cell leukemia : clinical and hematologic features of 16 cases. Blood, 50: 481492, 1977.

2 Hinuma, Y., K. Nagata, M. Hanaoka, M. Nakai, T. Matsumoto, K. I. Kinoshita, S. Shirakawa and I. Miyoshi, Adult T-cell leukemia: antigen in an ATL cell line and detection of antibodies to the antigen in human sera. Proc Natl Acad Sci U S A, 78: 6476-6480, 1981.

3 Poiesz, B. J., F. W. Ruscetti, A. F. Gazdar, P. A. Bunn, J. D. Minna and R. C. Gallo, Detection and isolation of type $C$ retrovirus particles from fresh and cultured lymphocytes of a patient with cutaneous T-cell lymphoma. Proc Natl Acad Sci U S A, $77:$ 7415-7419, 1980.

4 Levine, P. H., F. Cleghorn, A. Manns, E. S. Jaffe, L. Navarro-Roman, W. A. Blattner, B. Hanchard, M.
S. De Oliveira, E. Matutes, D. Catovsky and et al., Adult T-cell leukemia/lymphoma : a working point-score classification for epidemiological studies. Int J Cancer, 59 : 491-493, 1994.

5 Kinoshita, K., T. Amagasaki, S. Hino, H. Doi, K. Yamanouchi, N. Ban, S. Momita, S. Ikeda, S. Kamihira, M. Ichimaru and et al., Milk-borne transmission of HTLV-I from carrier mothers to their children. Jpn J Cancer Res, 78: 674-680, 1987.

6 Kondo, T., H. Kono, H. Nonaka, N. Miyamoto, R. Yoshida, F. Bando, H. Inoue, I. Miyoshi, Y. Hinuma and M. Hanaoka, Risk of adult T-cell leukaemia/lymphoma in HTLV-I carriers. Lancet, 2: 159, 1987.

7 Uchiyama, T., Human T cell leukemia virus type I (HTLV-I) and human diseases. Annu Rev Immunol, 15: 15-37, 1997.

8 Setoyama, M., F. A. Kerdel, G. Elgart, T. Kanzaki and J. J. Byrnes, Detection of HTLV-1 by polymerase chain reaction in situ hybridization in adult T-cell leukemia/lymphoma. Am J Pathol, 152: 683-689, 1998.

9 Mori, N., H. Sato, T. Hayashibara, M. Senba, T. Hayashi, Y. Yamada, S. Kamihira, S. Ikeda, Y. Yamasaki, S. Morikawa, M. Tomonaga, R. Geleziunas and N. Yamamoto, Human T-cell leukemia virus type I Tax transactivates the matrix metalloproteinase-9 gene: potential role in mediating adult T-cell leukemia invasiveness. Blood, 99 : 1341-1349, 2002.

10 Kohno, T., R. Moriuchi, S. Katamine, Y. Yamada, M. Tomonaga and T. Matsuyama, Identification of genes associated with the progression of adult $\mathrm{T}$ cell leukemia (ATL). Jpn J Cancer Res, 91 : 1103-1110, 2000.

11 de La Fuente, C., L. Deng, F. Santiago, L. Arce, L. Wang and F. Kashanchi, Gene expression array of HTLV type 1-infected T cells: Up-regulation of transcription factors and cell cycle genes. AIDS Res Hum Retroviruses, 16 : 1695-1700, 2000.

12 Ruckes, T., D. Saul, J. Van Snick, O. Hermine and R. Grassmann, Autocrine antiapoptotic stimulation of cultured adult T-cell leukemia cells by overexpression of the chemokine I-309. Blood, 98: 11501159, 2001.

13 Tanaka, Y., A. Wake, K. J. Horgan, S. Murakami, M. Aso, K. Saito, S. Oda, I. Morimoto, H. Uno, H. Kikuchi, Y. Izumi and S. Eto, Distinct phenotype of leukemic $\mathrm{T}$ cells with various tissue tropisms. J Immunol, 158 : 3822-3829, 1997.

14 Stetler-Stevenson, M., A. Mansoor, M. Lim, P. Fukushima, J. Kehrl, G. Marti, K. Ptaszynski, J. Wang and W. G. Stetler-Stevenson, Expression of matrix metalloproteinases and tissue inhibitors of metalloproteinases in reactive and neoplastic 


\section{K. Karube et al.}

lymphoid cells. Blood, 89: 1708-1715, 1997.

15 Matsuzaki, A. and A. Janowska-Wieczorek, Unstimulated human acute myelogenous leukemia blasts secrete matrix metalloproteinases. J Cancer Res Clin Oncol, 123 : 100-106, 1997.

16 Wake, A., Y. Tanaka, K. Nakatsuka, M. Misago, S. Oda, I. Morimoto and S. Eto, Calcium-dependent homotypic adhesion through leukocyte functionassociated antigen-1/intracellular adhesion molecule-1 induces interleukin-1 and parathyroid hormone-related protein production on adult T-cell leukemia cells in vitro. Blood, 86 : 2257-2267, 1995.

17 Tanaka, Y., K. Kimata, A. Wake, S. Mine, I. Morimoto, N. Yamakawa, H. Habuchi, S. Ashikari, H. Yamamoto, K. Sakurai, K. Yoshida, S. Suzuki and S. Eto, Heparan sulfate proteoglycan on leukemic cells is primarily involved in integrin triggering and its mediated adhesion to endothelial cells. $\mathbf{J}$ Exp Med, 184: 1987-1997, 1996.

18 Hayashibara, T., Y. Yamada, T. Miyanishi, H. Mori, T. Joh, T. Maeda, N. Mori, T. Maita, S. Kamihira and M. Tomonaga, Vascular endothelial growth factor and cellular chemotaxis: a possible autocrine pathway in adult T-cell leukemia cell invasion. Clin Cancer Res, 7 : 2719-2726, 2001.

19 Hasegawa, H., T. Nomura, M. Kohno, N. Tateishi, Y. Suzuki, N. Maeda, R. Fujisawa, O. Yoshie and S. Fujita, Increased chemokine receptor CCR7/ EBI1 expression enhances the infiltration of lymphoid organs by adult T-cell leukemia cells. Blood, 95: 30-38, 2000.

20 Yoshie, O., R. Fujisawa, T. Nakayama, H. Harasawa, H. Tago, D. Izawa, K. Hieshima, Y. Tatsumi, K. Matsushima, H. Hasegawa, A. Kanamaru, S. Kamihira and Y. Yamada, Frequent expression of CCR4 in adult T-cell leukemia and human T-cell leukemia virus type 1-transformed $\mathrm{T}$ cells. Blood, 99: 1505-1511, 2002.

21 Tanaka, Y., S. Mine, C. G. Figdor, A. Wake, H. Hirano, J. Tsukada, M. Aso, K. Fujii, K. Saito, Y. van Kooyk and S. Eto, Constitutive chemokine production results in activation of leukocyte function-associated antigen-1 on adult T-cell leukemia cells. Blood, 91 : 3909-3919, 1998.

22 Stetler-Stevenson, W. G., Dynamics of matrix turnover during pathologic remodeling of the extracellular matrix. Am J Pathol, 148: 1345-1350, 1996.

23 Stetler-Stevenson, W. G., Matrix metalloproteinases in angiogenesis: a moving target for therapeutic intervention. J Clin Invest, 103: 1237-1241, 1999.

24 Birkedal-Hansen, H., W. G. Moore, M. K. Bodden, L. J. Windsor, B. Birkedal-Hansen, A. DeCarlo and J. A. Engler, Matrix metalloproteinases: a review. Crit Rev Oral Biol Med, 4 : 197-250, 1993.

25 Simonetti, O., G. Lucarini, D. Brancorsini, P. Nita,
M. L. Bernardini, G. Biagini and A. Offidani, Immunohistochemical expression of vascular endothelial growth factor, matrix metalloproteinase 2, and matrix metalloproteinase 9 in cutaneous melanocytic lesions. Cancer, 95 : 1963-1970, 2002.

26 Vaisanen, A., H. Tuominen, M. Kallioinen and T. Turpeenniemi-Hujanen, Matrix metalloproteinase-2 (72 kD type IV collagenase) expression occurs in the early stage of human melanocytic tumour progression and may have prognostic value. J Pathol, 180 : 283-289, 1996.

27 Verdolini, R., P. Amerio, G. Goteri, L. Bugatti, G. Lucarini, B. Mannello, G. Filosa, A. Offidani, D. Brancorsini, G. Biagini and M. Giangiacomi, Cutaneous carcinomas and preinvasive neoplastic lesions. Role of MMP-2 and MMP-9 metalloproteinases in neoplastic invasion and their relationship with proliferative activity and p53 expression. J Cutan Pathol, 28: 120-126, 2001.

28 Dumas, V., J. Kanitakis, S. Charvat, S. Euvrard, M. Faure and A. Claudy, Expression of basement membrane antigens and matrix metalloproteinases 2 and 9 in cutaneous basal and squamous cell carcinomas. Anticancer Res, 19 : 2929-2938, 1999.

29 Vacca, A., S. Moretti, D. Ribatti, A. Pellegrino, N. Pimpinelli, B. Bianchi, E. Bonifazi, R. Ria, G. Serio and F. Dammacco, Progression of mycosis fungoides is associated with changes in angiogenesis and expression of the matrix metalloproteinases 2 and 9. Eur J Cancer, 33 : 1685-1692, 1997.

30 Okamoto, T., Y. Ohno, S. Tsugane, S. Watanabe, M. Shimoyama, K. Tajima, M. Miwa and K. Shimotohno, Multi-step carcinogenesis model for adult T-cell leukemia. Jpn J Cancer Res, 80 : 191$195,1989$.

31 Sato, H., T. Takino, Y. Okada, J. Cao, A. Shinagawa, E. Yamamoto and M. Seiki, A matrix metalloproteinase expressed on the surface of invasive tumour cells. Nature, 370: 61-65, 1994.

32 Ruangpanit, N., D. Chan, K. Holmbeck, H. Birkedal-Hansen, J. Polarek, C. Yang, J. F. Bateman and E. W. Thompson, Gelatinase A (MMP-2) activation by skin fibroblasts: dependence on MT1-MMP expression and fibrillar collagen form. Matrix Biol, 20 : 193-203, 2001.

33 Benyon, R. C., C. J. Hovell, M. Da Gaca, E. H. Jones, J. P. Iredale and M. J. Arthur, Progelatinase $\mathrm{A}$ is produced and activated by rat hepatic stellate cells and promotes their proliferation. Hepatology, 30 : 977-986, 1999.

34 Gilles, C., M. Polette, M. Seiki, P. Birembaut and E. W. Thompson, Implication of collagen type Iinduced membrane-type 1-matrix metalloproteinase expression and matrix metalloproteinase- 2 activation in the metastatic progression of breast car- 
Matrix metalloproteinase 2 expression in ATL skin lesions cinoma. Lab Invest, 76: 651-660, 1997. 